\title{
Clinical Observation of Four Prostate Stents Implantation Methods to Treat BPH Based on 52 Cases
}

\author{
Wenzeng Yang, Meng Zhang, Lili Qi, Quansheng Wang \& Jingyang Guo \\ Affiliated Hospital, Hebei University, Baoding 071000, China \\ E-mail: BDyangwenzeng@yahoo.com.cn
}

Received: December 1, 2010 Accepted: December 13, 2010 doi:10.5539/gjhs.v3n1p220

\begin{abstract}
In this article, by the clinical observation of four prostate stents implantation methods to treat BPH (Benign Prostatic Hyperplasia) based on 52 cases, the disadvantages and advantages of different methods are evaluated. For 52 BHP patients, four methods including the urocyst minimal incision prostate stents implantation, the prostate stents implantation in cystoscope orthophoria, the B ultrasonic cystoscope stents implantation, and the ultrasonic guidance prostate stents implantation are respectively adopted, and the prostate urethra lengths are in 4.0-5.6 cm, and the average length is $5 \mathrm{~cm}$. The results show that 52 patients were all successful in one implantation, and in the successive 10-45 months, two patients of them changed to the prostate cystostomy after operation, and one patient of them took out the stents and was adopted by the prostate enucleation above pubis. And the conclusions indicate that the B ultrasonic cystoscope prostate stents implantation method is better than other methods, with simple operation, short operation time, and definite treatment effect.
\end{abstract}

Keywords: BPH (Benign Prostatic Hyperplasia), Prostate stents implantation, Cystoscope, Ultrasonic guidance

BHP is the common disease in old males, and for those high-disk patients with old and weak, serious amalgamation medical clinic diseases, who can not accept operation, the treatment is very trouble. From 1998 to 2009, the Affiliated Hospital of Hebei University adopted the Ni-Ti memory alloy net stents implantation operation to treat 52 high-risk BHP patients, and four different implantation methods were respectively used, and the curative effects, complicating diseases, and recovery time after operation are objectively evaluated as follows.

\section{Materials and methods}

\subsection{Materials}

There are 52 cases, and the ages of these patients are in 52-86 years old, and the average age is 69 . There are 18 cases of BHP complicated with bladder stones, and the diameters of the stones are in $0.6-2.8 \mathrm{~cm}$, and there are 13 patients, who could not be treated by the lithotomy, and there are 12 patients with coronary heat disease, and there are 9 patients with obviously lower lung function. There are 29 BHP patients complicated with urinary infection, and the water germiculture and the drug sensitive test were used to correct the urinary infection. There are 34 BHP patients with higher PSA, and the prostate puncture biopsy was adopted to eliminate the prostate cancer. The scores of IPSS are in 23-31, and the average is 28. B ultrasonic is used to measure the length of the prostate urethra, and the result is in $4.0-5.6 \mathrm{~cm}$, and the average is $5.0 \mathrm{~cm}$, and the length of the stent should be length that the prostate urethra length subtracts $0.5-1.0 \mathrm{~cm}$. The urocyst contraction of these patients tested by the water hydromechanics is basically normal. In these cases, 8 of them were treated by the operation of the urocyst minimal incision prostate stents implantation, and 12 of them were treated by the operation of the prostate stents implantation in cystoscope orthophoria, 5 of them were treated by the operation of the B ultrasonic cystoscope stents implantation, and 27 of them were treated by the operation of the ultrasonic guidance prostate stents implantation.

The selected cases generally included those patients with bad conditions, who could not endure prostate electrocision or lithotomy. Without neurogenic urocyst, prostate middle lobe hyperplasia entering into urocyst obviously, urethrostenosis, prostate glands, bladder neoplasm, these patients had basically normal urocyst contraction, and bad curative effect of oral medicines.

\subsection{Operation methods}

(1) The operation of the urocyst minimal incision prostate stents implantation: adopt the horizontal position, and 
make a small incision at the position of one finger above public symphysis to enter into the urocyst, and put the stents introducer into the urocyst from the exterior entrance of urethra, and put the finger on the interior entrance of urethra, and push the stents to the urethra of the prostatic part when the stents contact with the finger, and inject warm salt water, so the stents will be placed in the urethra of prostate because of expansion, and the nearing end of the stents is parallel and level with the interior entrance of urethra, and then drop out the stents introducer. After operation, the ureter is placed in the prostate usually.

(2) The operation of the prostate stents implantation in cystoscope orthophoria: adopt the lithotomy position, and put the stents introducer into the urethra in cystoscope orthophoria, and inject warm physiological saline water, and push out the introducer after find the interior entrance of urethra, and the front end is apart from 2-3 mm with the interior entrance of urethra, and draw out the introducer slowly, and the down end of the stents is on the verumontanum, and when the stents position is proper, inject warm salt water to expand the stents.

(3) The operation of the B ultrasonic cystoscope stents implantation: adopt the lithotomy position, and after the urocyst is full, use the B ultrasonic to scan the pubis, and in cystoscope orthophoria, put the stents introducer into the urethra, and draw out the introducer slowly, and ensure that the down end of the stents is on the verumontanum, and use the ultrasonic to monitor that the stents has not entered into the urocyst, and inject warm salt water to expand the stents.

(4) The operation of the ultrasonic guidance prostate stents implantation: adopt the horizontal position, and after the urocyst is full, use the B ultrasonic monitoring to place the ultra-smooth guide wire into the urocyst, and place the tip of ureter with stents into the urocyst along the guide wire, and tract the guide wire and keep the tip of ureter stably, and draw back the epitheca, and when the front end of stents is revealed, inject warm water when drawing back the epitheca, and place the stents in the urethra of the prostatic part.

\subsection{Statistics processing}

The SPSS 13.0 software bag and the variance analysis are adopted in this article, and " $\mathrm{p}<0.05$ " is the difference, so the evaluation has the meaning of statistics.

\section{Results}

52 patients' were successful once implantations, and there was not serious haemorrhage, and all patients had different-level frequent micturition, urgent urination, odynuria, and urethra uncomfortableness. After the operation of the ultrasonic guidance prostate stents implantation, one patient had uroclepsia because of the constipation and the change of stents position after three days of the operation, and after the stents position was readjusted, the uroclepsia remitted. There were not cases with massive haemorrhage, epididymitis, and serious infection. The follow-up visits sustained 10-16 months, and the average time was 12.5 months, and three patients took orally anti-freezing medicines because of the coronary artery stents, and the hematuria time was too long after the operation, and after water drinking, these patients' hematuria gradually disappeared. Two patients were hospitalized again because of repeated urinary infection, and the stents were taken out, and the patients were treated by the anti-infection and the urocyst puncture cystostomy, without serious complicating diseases in urocyst and urethra.

Before the operation, the IPSS score were in 23-31, and the average score was 28 , and in three months after the operation, the IPSS scores were in 6-18, and the average score was 10 . Before the operation, the maximum water flow rates were in 7-12 ml/s, and the average rate was $9.4 \mathrm{ml} / \mathrm{s}$. In three months after the operation, the maxim water flow rates were in $14-19 \mathrm{ml} / \mathrm{s}$, and the average rate was $16.7 \mathrm{ml} / \mathrm{s}$. The residual urine quantity before the operation was in $230-840 \mathrm{ml}$, and the average was $425 \mathrm{ml}$. And the residual urine quantity after the operation was in 8-30 $\mathrm{ml}$, and the average was $19 \mathrm{ml}$. In these four different methods, the operation time and the hospital stays of the ultrasonic guidance prostate stents implantation operation were seriously shorter than other three methods ( $\mathrm{p}<0.05)$, and the comparison is seen in Table 1 .

\section{Discussions}

BPH is the common disease for old males, and the prostate electrocision operation through urethra is the gold standard to treat BPH, but the requirements for the patients' body condition are higher. More complications of the urocyst puncture cystostomy would occur, and patients' life quality would be further descended because they should take the pipes for life long. As a kind of method to remove the urinary tract obstruction in the prostate, the Ni-Ti memory alloy net stents implantation operation has many advantages such as simple operation, definite curative effect, relatively lower requirements for body conditions, and better biocompatibility (Zhou, 2008, P.2535-2538 \& Shen, 2008, P.3221-3224), and it suits for those high-risk patients with serious complication, bad constitution, old ages, and basically normal urocyst contraction, who could not endure operations. 
There are many prostate stents implantation methods, and they all can improve patients' urination symptoms and life quality, but they all have their own indications and relative merits.

(1) The operation of the urocyst minimal incision prostate stents implantation: it is mainly suits for those patients with complicated bladder calculi which could not be taken out by the cystoscope through the urethra. There were 8 patients with complicated bladder calculi to use this method, and its advantage is that the finger can be used to position when taking out the bladder calculi, and the stents position is relatively exact, and the technical level and other special equipments are not demanded, and it can be easily applied in basic hospitals. The disadvantages include that this method needs to incise the urocyst, and the wounds would be increased relatively, and the operation risk is higher, the haemorrhage in the operation often occurs, and after the operation, the ureter needs to be hold, which will increase the infection rate, and the hospital stays are too long.

(2) The operation of the prostate stents implantation in cystoscope orthophoria: its advantages include that it could observe the urethra and the interior of the urocyst in the cystoscope, and the lesions in the urinary tract could be found and treated correspondingly, and the stents placement in orthophoria could avoid the placement error because of iconography monitoring, increasing the success rate and the clinical operability (Taksin L, 2007, P.954-959). The disadvantage is that only the back end of the stents could be observed in the cystoscope orthophoria, and the possibility that the stents charges into the urocyst would be increased, and the operation in the cystoscope needs special position, and if the patient could not adopt the lithotomy position, this method could not be used, and this method could induce relative complications about the cystoscopy, for example, the prostate haemorrhage and the urethra harm could not be judged because of hematuresis after operation or the stents implantation.

(3) The operation of the B ultrasonic cystoscope stents implantation: its advantage is that it could directly observe the front end position of the stents in the ultrasonic monitoring, and the position of the stents is relatively exact. The disadvantages includes that the operation is relatively complicated, and the ultrasonic measurement should match with the doctor, and the cystoscope operation may induce certain complications.

(4) The operation of the ultrasonic guidance prostate stents implantation: its advantage is that in the ultrasonic guide, the stents implantation could be observed dynamically, without special position, cystoscope, or other operation equipments. According to the ultrasonic measurement, the factors influencing the curative effect after the stents implantation could be objectively judged, and the treatment plan can be modified in time (Zhang, 2006, P.109-111).

The key of the operation of the ultrasonic guidance prostate stents implantation is to exactly measure the urethra length in the prostatic part and exactly place the stents. The urethra length of prostate could be measured by the rectum B ultrasonic or the cystoscope, and because the rectum B ultrasonic has no wounds, so it is usually adopted. The standard of the stents is estimated according to the measured prostate urethra length, and generally, the stents with shorter $0.5-1.0 \mathrm{~cm}$ length than the prostate urethra is selected. It is very important to exactly place the stents for the operation effect, and if the placement position is too high, entering into the urocyst, the part that the urethra mucosa would not cover will easily form stones, even induce the stents blocking. And if the placement position is too slow, stressing the sphincter out of the urethra, and uroclepsia will be complicated. The ideal stents placement position should be that the distance from the near end of the stents to the vesical neck is about $0.5 \mathrm{~cm}$, and the distance from the far end of the stents to the prostate tip is about $0.5 \mathrm{~cm}$. After the operation, patients should avoid forcedly defecating to shift the stents, and in the cases, one patient shifted down the stents because of constipation in three days after the operation, and the sphincter out of the urethra was stressed to induce the uroclepsia, and through readjustment of the stents position, the uroclepsia remitted. Because the prostate stents implantation could not restrain the hyperplasia of prostate tissue, and the materials of the stents could influence the forward effect of the operation to some extent. In 52 cases, all patients adopted the Ni-Ti memory alloy net stents, and the forward effects were very good, without granulation tissue hyperplasia and urethrostenosis in the prostate part.

In a word, the prostate stents implantation operation is a simple, safe, and effective method (Taksin L, 2007, P.954-959 \& Muschter R, 2008, P.155-165), and the operation of the B ultrasonic guide stents implantation is very simple, without special equipments, and like catheterization, it is ideal implantation method. The success and the optimal treatment effect of the stents implantation are determined by the patient selection and the method and experience of stents implantation (Vanderbrink BA, 2007, P.1-6). With the development of the prostate stents implantation technology, the clinical application will be more mature and wide. 


\section{References}

Muschter R, Reich O. (2008). Surgcal and instrumental management of benign protatic hyperplasia. Urology. No.47(2). P.155-165.

Shen, Jihong \& Jiang, Yongneng et al. (2008). Endourethral Ni-Ti alloy stenting under X-ray or cystoscope for prostatic hyperplasia: Biocompatibility to host. Journal of Clinical Rehabilitative Tissue Engineering Research. No.17(12). P.3221-3224.

Taksin L, Vidart A, et al. (2007). Palliative treatment of symptomatic benign prostatic hyperplasia by permanent urethral stern in high surgical risk patients. Prog Urol. No.17(5). P.954-959.

Vanderbrink BA, et al. (2007). Prostatic stents for the treatment of benign prostatic hyperplasia. Curr Opin Urol. No.17(1). P.1-6.

Zhang, Zidong \& Yao, Ziqing et al. (2006). Clinical Application of Ultrasonography in Nicklel-titanium Alloy Stenting for Hyperplasia of Prostate. Inner Mongolia Medical Journal. No.38(2). P.109-111.

Zhou, Tiangui \& Xia, Jinsheng et al. (2008). Application of Prostate Scaffold in Treating Prostatic Hyperplasia. Journal of Clinic Rehabilitative Tissue Engineering Research. No.13(12). P.2535-2538.

Table 1. Comparisons of the operation times and hospital stays for different implantation methods (Comparing with other three methods, ${ }^{*} \mathrm{p}<0.05$ )

\begin{tabular}{|c|c|c|c|c|}
\hline & $\begin{array}{c}\text { Prostate stents } \\
\text { implantation in } \\
\text { cystoscope } \\
\text { orthophoria }\end{array}$ & $\begin{array}{c}\text { B ultrasonic } \\
\text { cystoscope stents } \\
\text { implantation }\end{array}$ & $\begin{array}{c}\text { Urocyst minimal } \\
\text { incision prostate } \\
\text { stents implantation }\end{array}$ & $\begin{array}{c}\text { Ultrasonic } \\
\text { guidance prostate } \\
\text { stents implantation }\end{array}$ \\
\hline $\begin{array}{c}\text { Operation } \\
\text { time (min) }\end{array}$ & $25 \pm 10$ & $25 \pm 7$ & $30 \pm 10$ & $10 \pm 5^{*}$ \\
\hline $\begin{array}{c}\text { Hospital } \\
\text { stays (d) }\end{array}$ & $5 \pm 1$ & $5 \pm 2$ & $10 \pm 2$ & $3 \pm 1^{*}$ \\
\hline
\end{tabular}

